J. Linguistics 36 (2000), 26I-297. Printed in the United Kingdom

(C) 2000 Cambridge University Press

\title{
Presupposition, negation and trivalence
}

\author{
PIETER A. M. SEUREN \\ Max Planck Institute for Psycholinguistics, Nijmegen \\ (Received I I January I999; revised I8 August I999)
}

\begin{abstract}
Close inspection of presupposition( $=\mathrm{P}$-)cancelling and other metalinguistic negation data shows that natural language semantics must be (at least) trivalent, with the values 'true', 'minimally false' (assertion failure) and 'radically false' (presupposition failure). It is argued that presupposition is a semantic phenomenon originating in a distinction between two kinds of satisfaction conditions for predicates, the PRECONDITIONS generating presuppositions, and the UPDATE CONDITIONS generating classical entailments. The trivalence of language is a natural consequence of the acceptance of occasion sentences in an incremental Discourse Semantics. The logical properties of sentences are considered secondary and derived from their semantic properties. These include, besides propositional content, a speech act quality, specifying the personal commitment taken on by the speaker not only in respect of the propositional content, but also with regard to the linguistic forms selected. It is suggested that the classical truth-functional operators should be redefined as instructions under speech act commitment. The negation operator is singled out: it is redefined as an instruction to reject either an incrementable sentence, which may be a comment about a form used or to be used (P-preserving negation), or an already incremented sentence to be removed from the discourse along with some presupposition (P-cancelling negation).
\end{abstract}

\section{INTRODUCTION}

Since the spate of publications during the I980s around the incessantly intriguing question of presupposition and negation in natural language, a few more articles dealing with this topic, written mostly by authors with a strong allegiance to pragmatics, have recently seen the light. Although I do not share that allegiance, I wish to raise a few points in this regard, which I consider of central importance. While much of what is said strikes one as intuitively reasonable or even plausible, one notices at the same time a surprising casualness in respect of the formal and empirical underpinnings of the positions defended. This is regrettable, since a more precise focusing on the formal and empirical aspects will clarify the issues, eliminate some positions as untenable, and, most importantly, lead to fruitful new insights, in particular with regard to the function of logic in the semantics of natural language.

The precise function of logic in the semantic and/or grammatical analysis of natural language has been a bone of contention for many centuries, and 
it still is, despite the widely accepted view that the model-theoretic semantics developed in the context of modern logic is the right model for a semantics of natural language. I keep telling myself, and, I believe, with good arguments, that logic is, though indispensable, more collateral than is normally thought. Yet I cannot help being constantly struck by the power and the inspiration that come from logical arguments and analyses. This is what has happened again in this case. I want to show that a fundamental rethinking of the premisses upon which logic and semantics are built, in the light of the phenomena that come with presuppositions in natural language, opens up a totally new landscape where presuppositions along with a host of other phenomena, like metalinguistic usage, are natural denizens, and no longer unwanted elements in an otherwise well-regulated system.

\section{CARSTON'S ANALYSIS}

Carston (I998) provides perhaps the best handle to start the discussion. This recent paper is representative of a widespread body of opinion, but also, not untypically, lacking in formal precision and, to some extent, also in empirical detail. On the other hand, the conclusions reached in this paper appear not only to be intuitively appealing but also to stand up under formal scrutiny. We will thus, in principle, reject Carston's way of reasoning, but uphold most of her conclusions.

Carston discusses the question of whether presupposition is a pragmatic or a semantic phenomenon, and in particular whether the semantics of the natural language negation operator is sufficiently defined by that of the propositional negation operator known in standard bivalent logic. Her position is that standard bivalent logic is indeed adequate for the semantic description of natural language, and that presuppositional phenomena, including presupposition $(=\mathrm{P})$-cancelling, as well as other metalinguistic uses of the negation are to be explained pragmatically. Carston is a true Gricean, in that she prefers to leave the application of standard logic to the semantics of natural language as it is, and places the burden of explanation of all deviant phenomena squarely on pragmatics.

In order to clarify and summarise the various positions 'on the market' (surely a timely exercise), Carston distinguishes between (a) the 'Griceans', for whom presuppositions are just entailments with some pragmatic sideeffects and negation is semantically defined as the standard bivalent operator equally allowing for pragmatic side-effects, and (b) the 'semantic presuppositionalists', for whom presupposition is a semantic phenomenon and negation is P-preserving. She points out that both parties wish to settle for a single negation operator, which, however, the presuppositionalists take to be P-preserving, but the Griceans P-cancelling. She gives the following schematic rendering of the opposition (I998: 3 I 5, 339): 
(I) Griceans

Presuppositionalists: (a) semantically: not [the $F$ is $G$ ] (P-cancelling) via pragmatics: [the $\mathrm{F}$ is not-G] (P-preserving)

(b) semantically: [the $\mathrm{F}$ is not-G] (P-preserving) via pragmatics: not [the $F$ is $G$ ] (P-cancelling)

There is, however, an important caveat (Carston I998: 3I 5), in that for the Griceans the P-cancelling form 'not [the F is G]' contains the standard bivalent negation ' $\neg$ ' known from logic, whereas for the presuppositionalists (mainly Horn and Burton-Roberts) the form 'not [the F is G]' contains a 'special (pragmatically derived) metalinguistic negation'. This is important, since it begs the question of whether language has one single negation operator: the tenability of that position now depends on the tenability of the pragmatic reduction of standard not $(\neg)$ to a metalinguistic not. Much of Carston's argument is then devoted to showing that Horn's and BurtonRoberts' pragmatic reductions are not tenable (whereby she uses many arguments presented earlier in Seuren 1988, I990). She then proposes her own position, which doubles the burden of pragmatics (I998: 340):

(2) semantically: not [the $\mathrm{F}$ is $\mathrm{G}$ ]

(P-cancelling)

via pragmatic processing (a): [the $\mathrm{F}$ is not-G] (P-preserving)

via pragmatic processing (b): not ["the F is G"] (P-cancelling, metalinguistically)

At this point a few questions may be raised. I will concentrate first on (Ia), leaving ( $\mathrm{Ib}$ ) and (2) with its form 'not ["the F is G"]' to later on. Consider the P-preserving form 'the $F$ is not-G', figuring as the Gricean pragmatic reanalysis of the P-cancelling form 'not [the $F$ is $G$ ]'. The first question is: how can the form 'the $\mathrm{F}$ is not-G' be seen to be P-preserving? This is a legitimate question, since, one way or another, the preservation of presuppositions must be seen to follow from something. And since Carston proposes two different forms, one P-cancelling and one P-preserving, it is worth investigating whether this semantico-pragmatic difference can be pinned down to a formal difference.

One possible reason for assuming that the form 'the $\mathrm{F}$ is not-G' is Ppreserving is that it can be read as saying that the entity referred to by the expression 'the $F$ ' fails to satisfy the conditions posed by the predicate ' $G$ ' and thus is an element in the complement-set of G, 'not-G'. On this reading the existence of the entity referred to by 'the $F$ ' is not called into question, so that one may say that the existential presupposition has been preserved.

But then one wonders about the kind of logic involved. It would seem that the form ' the $\mathrm{F}$ is not- $\mathrm{G}$ ', interpreted as above, requires a non-bivalent logic. This is because the totality of possible situations is not exhausted by the $F$ being or not being a member of the set denoted by G (e.g. by the king of France being or not being a member of the set of bald entities). It is also possible, of course, that there simply is no F, no king of France, in which case neither 'the $F$ is $G$ ' nor 'the $F$ is not- $G$ ' is true (under the interpretation 
given). This means that the not used here, properly reconverted into a propositional operator, cannot be the simple toggle between truth and falsity that it is in standard bivalent logic: it is a not which toggles between sets of entities and their complements, and thus preserves existential entailment. It thus looks as if, in her (Ia), Carston has implicitly introduced two truthfunctionally distinct negations.

Moreover, one wonders how this account fares with other categories of presupposition. Carston starts her article (1998: 309) by quoting three sentences, each demonstrating a cancellation of a well-known presuppositional category:

(3) (a) The king of France isn't bald - there is no king of France.

(b) I don't regret inviting him - he jolly well gatecrashed.

(c) I haven't stopped smoking - I've never smoked in my life.

The first sentence, (3a), exemplifies an existential presupposition, and one may perhaps accept that the form 'the $F$ is not- $G$ ' allows for an interpretation that preserves that presupposition. But why should this form, under that interpretation, preserve the presupposition of $(3 \mathrm{~b})$ or $(3 \mathrm{c})$ ? $(3 \mathrm{~b})$ would read as something like 'speaker fails to satisfy the conditions posed by the predicate "regret inviting him", and is thus an element in the complementset of that predicate'. But that complement-set contains all entities of which (whom) it cannot be said in truth, for whatever reason, that they regret inviting him, including those that never invited him at all. In other words, the factive presupposition of ( $3 b)$ appears to be lost. Likewise for (3c), which assigns the speaker (' $I$ ') to the set of all those entities that are not ex-smokers. And this set includes those who never smoked at all. So here, too, the form 'the $\mathrm{F}$ is not-G' appears to fail to preserve the presupposition induced by the aspectual verb stop.

\section{The CONJUNCTION ANALYSis}

One might propose to save Carston's position by means of the so-called 'conjunction analysis': the P-carrying sentence is analysed as a conjunction consisting of, first, the presupposition(s) and, secondly, the P-carrying sentence itself. So, if we take ' $\mathrm{B}_{\mathrm{A}}$ ' to stand for a sentence $\mathrm{B}$ presupposing $\mathrm{A}$, $\mathrm{B}_{\mathrm{A}}$ is analysed as ' $\mathrm{A}$ and $\mathrm{B}_{\mathrm{A}}$ '. This appears to provide a general account for $(3 \mathrm{a}-\mathrm{c})$, whose non-negated versions can now be analysed as, respectively:

(4) (a) $\exists \mathrm{x}[\mathrm{KoF}(\mathrm{x})] \wedge \operatorname{Bald}($ the $\mathrm{x})$

(there is a king of France and he is bald)

(b) Invite(I,him) $\wedge$ Regret(I, [Invite(I,him)] (I invited him and I regret I did)

(c) Before $[\operatorname{Smoke}(\mathrm{I})] \wedge$ Now $[\neg[\operatorname{Smoke}(\mathrm{I})]]$ (I smoked before and I don't smoke now)

Now the negation can be placed over the conjunction as a whole (wide 
scope), or over just the second conjunct (narrow scope), a possibility alluded to in Carston (1998: 3II). The wide scope negation is then said to be Pcancelling, while the narrow scope negation is taken to be P-preserving, because in the narrow scope reading the presupposition (i.e. the first conjunct) is entailed, and only the second conjunct is negated. Rephrasing (Ia), one can now say that, for the Griceans, the semantically 'genuine' Pcancelling not occurs in ' $\operatorname{not}\left[\mathrm{A}\right.$ and $\left.\mathrm{B}_{\mathrm{A}}\right]$ ', while pragmatically reanalysed $\mathrm{P}$ preserving not is found in ' $A$ and $\operatorname{not}\left[\mathrm{B}_{\mathrm{A}}\right]$ '. Carston's form 'the $\mathrm{F}$ is not-G' now corresponds to 'there is an $F$, and not [the $F$ is $G$ ]', or, since we are trying to be precise, ' $\exists \mathrm{x}[\mathrm{F}(\mathrm{x})] \wedge \neg[\mathrm{G}($ the $\mathrm{x})]$ '.

Although this looks like an attractive solution, there are some problems. The first problem is serious, but not insurmountable. It is presented by the fact that the conjunction analysis requires some form of definite determiner in the formal language of analysis. One notices that in (4a) the expression the $x$ in 'Bald(the $\mathrm{x})$ ' is a referring term. This is not accepted in standard Predicate Calculus, which does not contain definite determiners, as it wants to avoid the complications of a reference function. (4a) thus lacks a welldefined semantic interpretation in standard Predicate Calculus. Leaving out the determiner the leads to unwellformedness, since 'Bald(x)' is not a proposition but a propositional function standing for the set of bald entities, and cannot, therefore, be conjoined with the proposition ' $\exists \mathrm{x}[\mathrm{KoF}(\mathrm{x})]$ '. In fact, Russell (1905) did not propose the form (4a) but rather (without the uniqueness clause) $\exists \mathrm{x}[\mathrm{KoF}(\mathrm{x}) \wedge \operatorname{Bald}(\mathrm{x})]$, where both occurrences of $x$ are properly bound.

The predicament is that, on the one hand, the Russell analysis does not apply to other categories of presupposition, as in $(3 \mathrm{~b}, \mathrm{c})$, but on the other hand, the conjunction analysis, which does apply to $(3 \mathrm{~b}, \mathrm{c})$, is not usable for (3a) in the terms of established logic. If we want to continue making use of logic as an instrument in semantics, this dilemma must be solved. It can be solved if we enrich or extend standard Predicate Calculus with a device that allows for definite descriptions like the king of France (and also for anaphoric expressions like the $x$ ). This, however, goes against a central current in modern logic, where it is considered essential that propositions be interpretable, i.e. can be assigned a truth value, without any appeal to context or other contingent circumstances. The semantic interpretation of logical formulae must, in other words, be entirely compositional. In this programme, whose main representatives are Russell and Quine, all propositions must be expressible as 'eternal' sentences, and all apparent 'occasion' sentences in natural language must therefore be translated into logical forms not containing any element whose interpretation is dependent on context or situation (see also section 6 below). Since the interpretation of definite determiners clearly depends on context and/or situation, they must be eliminated from logical analysis. Since this is now the standard view, we must have good arguments if we want to reintroduce them. 
But such arguments are not hard to find. First of all, if one investigates the grounds on which philosophers like Russell or Quine maintain that logic should be 'eternal' in the sense described, one finds surprisingly little. All arguments boil down, in the end, to an anxious and absolute determination to keep logic bivalent and compositional. They knew well that this is impossible in a logic operating with propositions that require contextual 'anchoring', i.e. external information (from discourse, speech situation or available world knowledge) for the fixing of reference relations and thus for the assignment of truth values. Contextual anchoring, in other words, is a threat to both bivalence and compositionality. But will the loss of bivalence and compositionality lead to the destruction of logic? Not at all. It is perfectly possible to build into established logic (and into its mathematical foundations) elements whose identification is not given within the logic but is provided from without. Standard logic already does that: the identification of the element 'universe of discourse', for example, is dependent on any practicable application, and any propositional or predicate variables stand for elements to be identified by nonlogical means. In a parallel fashion one can introduce partial 'universes' of discourse, determined by contingent factors but subject to general constraints of a logical nature. Such partial subuniverses will then, in actual life, contain the information required for adequate contextual anchoring, i.e. the assignment of reference relations and other conditions that must be fulfilled for a proper interpretation. We shall see below that such a measure amounts to an extension or further refinement of standard logic, not to its destruction or replacement.

Since there is massive evidence that any type-level logical analysis of sentences severely underdetermines actual interpretation, which proves essentially dependent on contextual factors, there can be no objection to the introduction of formal elements, like definite determiners, which explicitly appeal to external, noncompositional information, into the analytical language of logic and/or semantics. This being so, it would seem that there is nothing wrong in principle with an analysis like (4a), which contains the referring operator the. All that is required is a mechanism for the integration of this operator into the machinery of logic. The conjunction analysis, of which (4a) is an example, will then be context-dependent to the extent that definite determiners are, but still compositional to the extent that it can be applied merely on the basis of the form of any P-carrying sentence $B_{A}$ : given a procedure for the identification of the presupposition(s) $\mathrm{A}$, the analysis consists simply in the construction of the form ' $\mathrm{A}$ and $\mathrm{B}_{\mathrm{A}}$ '.

It thus looks as if the conjunction analysis appears a serious candidate for an analysis of presuppositions. Unfortunately, however, it cannot be. It suffers from a further problem, which is less of a formal than of an empirical nature, and, it seems, fatal. It shows up when P-carrying sentences are placed under an emotive intensional operator like be afraid, be surprised or hope: 
(5) (a) Carol is afraid that the thief is her brother.

(b) Bob was surprised that I regretted inviting him.

(c) Alice hopes that I have stopped smoking.

Clearly, these sentences do not mean what the conjunction analysis says they should mean:

(6) (a) Carol is afraid that there is a thief and that he is her brother.

(b) Bob was surprised that I had invited him and that I regretted I did.

(c) Alice hopes that I smoked before and that I don't smoke now.

What Carol is afraid of, in (5a), is specifically the possibility of her brother being a thief, not the existence of a thief, and analogously for the other two sentences: the emotive operator applies to the P-carrying clause, not to its presupposition(s). We know from presupposition theory that presuppositions tend to be projected through such operators into the main 'domain', so that (5a) would, in the projected reading, amount to 'there is thief, and Carol is afraid that he is her brother', and likewise for $(5 \mathrm{~b}, \mathrm{c})$. But projection may be blocked, for example when the main discourse domain contains the information that what is said in the presupposition is not the case (for example, there is no thief). In that case the presupposition remains restricted to an appropriate intensional subdomain, as in (7):

(7) Carol is convinced that someone has his fingers in the till, but she won't believe that the thief is her brother.

Clearly, however, the machinery for getting presuppositions in place is now no longer compositional but context-dependent, which makes the conjunction analysis, which professes compositionality, unfit to act as a semantic analysis of P-carrying sentences. ${ }^{1}$ The conjunction analysis is, therefore, not viable and must, after all, be rejected.

\section{NOT AS A PROPOSITIONAL OPERATOR: NEGATION-SPLIT OR ARGUMENT-SPLIT}

Where does this leave us with regard to Carston's analysis? If the idea of the conjunction analysis must be given up, and the literal form 'the $F$ is not-G' won't do for cases like $(3 b, c)$, there appears to be no other alternative than to revert to the use of not as a propositional operator in all cases, as in the Fregean structure 'not [the $F$ is G]'. It is well-known that the propositional operator not, as in ' $\operatorname{not}[\mathrm{A}]$ ', where $\mathrm{A}$ is a proposition, can be converted, under certain conditions, into a predicate operator as in 'not-G', where $G$ is

[I] A proposal as to how presupposition projection is to be dealt with in a context-dependent way is made e.g. in Seuren (I985) 
a predicate, but such a conversion has the disadvantage of being less expressive of the logical power of not, since not cannot be so converted when it takes further operators, such as quantifiers, in its scope. So the FregeRussell syntax, with not as a propositional operator, has clear advantages. If we adopt that syntax, both analyses in (Ia) are of the form 'not [the F is G]'. But how do we then account for the fact that this structure is sometimes Ppreserving and sometimes P-cancelling?

One possible answer is that the P-preserving cases involve a non-bivalent negation, whereas the P-cancelling cases involve a different not, which for Carston is the standard bivalent ' $\neg$ ' (it may, for that matter, also be the radical negation ' $\simeq$ ' discussed e.g. in Seuren I985, I988). On this analysis at least two different types of negation, and of logic, are involved, one of which is P-preserving, and the other is not. Let us write the P-preserving form as " [the F is G]' and the P-cancelling form as 'NOT [the F is G]'.

Another possible answer consists in maintaining the unity of negation, which is then considered P-preserving, i.e. ' ', and making a distinction in the form of the argument proposition 'the F is G', which can be taken to be used in a direct, 'descriptive' sense, or else in a metalinguistic sense in which ["the $F$ is G"] stands for an object about which some negative comment is made. This is what underlies Carston's proposal of the form "not ["the F is G"]' in (2b) above, and also the proposal made in Seuren (I988). The difficulty with this solution, however, is that a form like ["the F is G"] does not express a proposition but denotes a linguistic object. In terms of linguistic analysis: it is not an S but a definite NP. But the operator ' ' requires a proposition (i.e. an S-structure), and is meaningless as an operator over a definite description. This obstacle may not be insurmountable, but it requires some drastic reanalysis, as well as solid empirical support. This 'argumentsplit' option is, in fact, the most difficult one to implement. Yet one cannot rule out a priori the possibility that it will, in the end, prove to be the correct one.

Both the negation-split and the argument-split solution contain the promise of an answer to the question raised above about presuppositions other than the existential ones in the form 'the $F$ is not- $G$ ', since both solutions involve the P-preserving negation ' $\sim$ ': the form ' $\sim$ [the $F$ is G]' now generally preserves all presuppositions. At the same time it is clear that both solutions also require that the principle of bivalence be given up.

\section{Reluctance to accept nonbivalence}

Strangely, however, the majority of logicians, semanticists and pragmaticists prove extremely reluctant even to consider the possibility of nonbivalence for language. For them, the bivalence principle is inviolate. Why should that be so? The combined authority of Aristotle, Frege and Russell clearly plays a role. It is an ironical fact that there is no scientific discipline where authority 
plays such an important role as in logic, which is precisely the discipline that argues explicitly against the fallacy of authority-based arguments. But awe is not only felt with regard to the great masters, there is also an element of awe in the presence of what are felt to be the arcane mysteries of the foundations of logic and mathematics, which one should not try and tinker with. If that is so, all we can say is that any such reluctance to review those foundations is irrational and misguided, since these matters are as open to critical review as any other matter - provided, of course, that the review be carried out with due care, that is, professionally.

One unfortunate result of this situation is that authors in the field of pragmatics-cum-semantics sometimes make unfounded statements about non-bivalence. A typical example is the following. Carston emphatically rejects the possibility of two negations (in her case ' $\neg$ ' and ' ', as we have seen), on the grounds that this would somehow be contradictory. Approvingly referring to Burton-Roberts, she writes (p. 3I2):

He argues convincingly, against the received view, that it is contradictory to maintain both that natural languages are semantically presuppositional and that they have a negation operator that cancels presuppositions, as in the examples [( $3 \mathrm{a}-\mathrm{c})]$. This, he says, is tantamount to inventing a second operator to mop up a set of counter-examples to the thesis that natural languages are presuppositional, a thesis which entails that their negative sentences cannot be P-cancelling.

The same faulty argument is presented in Gazdar (1979: 66):

The proponent of a nonbivalent semantics is faced with a dilemma. If he chooses a negation operator which predicts the presuppositions in John doesn't regret having failed, then he loses the ability to account for the possible TRUTH of John doesn't regret having failed, because, in fact, he passed. But if he chooses a negation operator which allows for the TRUTH of $\langle$ the latter $\rangle$, then he loses the ability to predict the presupposition of $\langle$ the former $\rangle$, which is what the nonbivalent semantics was introduced to do in the first place.

It is easy to see that there is no such contradiction at all. A mere distinction between two different kinds of falsity (as already proposed in principle in Dummett I98 I: 42 I; see section 9 below) suffices to create the logical space for two negations, one P-preserving and one P-cancelling. By definition, a Ppreserving negation treats presuppositions as necessary truths, not for the set $\mathbf{U}$ of all possible situations, but for a restricted subuniverse $\mathbf{U}_{\mathbf{A}}$, which is determined, for each sentence A, by the presuppositions of A. The Ppreserving negation over a sentence A thus 'toggles' within $\mathbf{U}_{\mathbf{A}}$ and has no effect on those sentences whose truth requires a situation outside $\mathbf{U}_{\mathbf{A}}$. If the presuppositions of $\mathrm{A}$ are true but $\mathrm{A}$ itself is not, then the actual situation $s_{a}$, the one that makes A false, is within $\mathbf{U}_{\mathbf{A}}$ but outside the set of situations that 
make A true, or $/ \mathrm{A} /$, that is, $s_{a}$ is in the complement of $/ \mathrm{A} /$ within $\mathbf{U}_{\mathbf{A}}$. On the other hand, if not even the presuppositions of $\mathrm{A}$ are true, so that $\mathrm{A}$ itself stands no chance of being true, $s_{a}$ is in the complement of $\mathbf{U}_{\mathbf{A}}$ within $\mathbf{U}$, as is shown in Figure I.

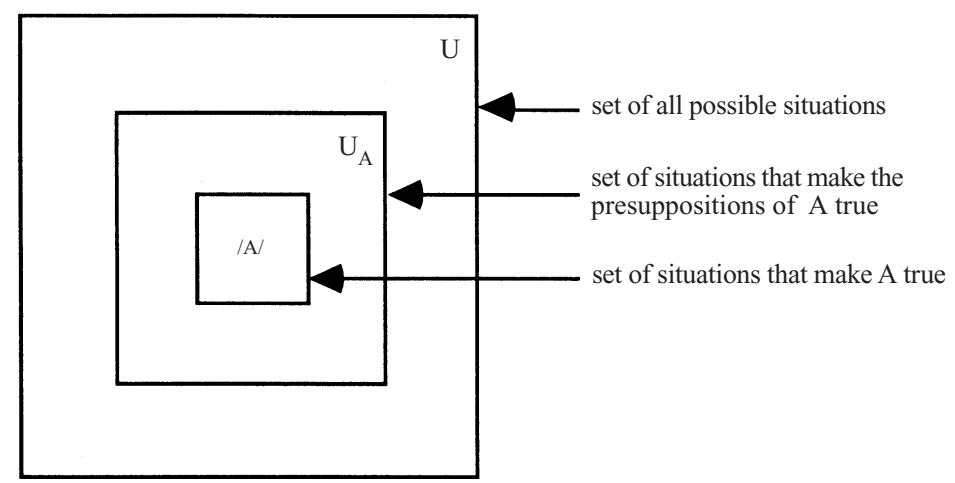

Figure $I$

Situation space and two complements for proposition A

We may thus distinguish two different kinds of falsity where standard truth theory has only one. If one takes away that distinction one is back in standard logic. Since there are now two different kinds of falsity, there is room for two negations, one $\mathrm{P}$-preserving negation, as in $\sim \mathrm{A}$, which says that truth lies in the complement of /A/ within $\mathbf{U}_{\mathrm{A}}$, and one which says that truth lies in the complement of $\mathbf{U}_{\mathbf{A}}$ within $\mathbf{U}$, which amounts to saying that A suffers from presupposition failure. The former is my minimal negation ' $\sim$ ', the latter is my radical negation ' $\simeq$ '. For any sentence $A$, the set of situations that make $\simeq \mathrm{A}$ true plus the set of situations that make $\sim \mathrm{A}$ true is precisely the set of situations that make $\neg \mathrm{A}$ true. That is, the classical negation $\neg$ is the union of the minimal and the radical negation: $\sim \mathrm{A} \vee \simeq \mathrm{A}$ $\equiv \neg \mathrm{A}$.

It is, therefore, not at all 'contradictory to maintain both that natural languages are semantically presuppositional and that they have a negation operator that cancels presuppositions.' On the contrary, the very thesis that natural language is semantically presuppositional creates the logical space required for the definition of a negation operator that cancels presuppositions. Whether any such P-cancelling 'radical' negation is the right answer to linguistic phenomena of P-cancelling is another question. I do not believe it is (see section Io). But the assumption of two logical negations in a non-bivalent system is perfectly rational and not doomed to failure from the start because of some alleged 'contradiction' lurking below the surface. More importantly, however, the investigation into the logical space of multivaluedness has yielded formal insights that prove highly revealing and 
PRESUPPOSITION, NEGATION AND TRIVALENCE

much more stringent as an account of presupposition and discourse structure than anything produced so far in the context of pragmatic theorizing.

\section{TRUTH in LANGUAGE is NOT BIVALENT: AN EMPIRICAL ARGUMENT}

Let us look further into this matter. IT MUST BE ESTABLISHED FIRST, AS A MATTER OF EMPIRICAL FACT, THAT TRUTH IN NATURAL LANGUAGE IS NOT BIVALENT, AND THAT NEGATION IN LANGUAGE DOES NOT SIMPLY TOGGLE BETWEEN TRUTH AND GENERIC FALSITY.

Before the argument can be presented, the notion of bivalence has to be made more precise. The Aristotelian PrinCIPLE OF Bivalence, also known as the PRINCIPLE OF THE EXCluded THIRD (PET), applies first and foremost to the Aristotelian theory of truth as correspondence. Its application to logic is secondary. For Aristotle, truth and falsity are properties of propositions expressed in sentences, in such a way that PET holds. PET consists of two independent subprinciples stated below.

PRINCIPLE OF THE EXCLUDED THIRD

(i) Principle of Complete Valuation: all propositions always have a truth value.

(ii) Principle of Binarity: there are exactly two truth values, 'true' and 'false'; there are no values in between, and no values outside 'true' and 'false'. The Principle of Binarity comprises the PrinciPle OF THE EXCLUDED MidDLE (PEM), which says only that there are no values between 'true' and 'false', and says nothing about possible values beyond simply 'true' and 'false'. ${ }^{2}$

The Principle of Complete Valuation holds trivially if one follows the tradition and defines a proposition as the bearer of a truth value. Then, obviously, it makes no sense to speak of propositions without a truth value. If logic is then considered to be a truth-preserving calculus of propositions, it follows that logic, any logic, must by definition satisfy the Principle of Complete Valuation. One may, however, also conceivably consider logic to be a truth-preserving calculus of ASSERTIONS, and allow into one's logic assertions that do not express propositions since they lack a truth value. In that case, the LOGIC does not satisfy the Principle of Complete Valuation, since it contains objects that lack a truth value. This course was followed in Strawson (1950), and gave rise to the notion of a gapped bivalent logic. (Whether Strawson also meant to apply the notion of 'gapped bivalence' to the theory of truth is not clear, but this point can rest unclarified.)

[2] PET and PEM are often confused in the literature, mainly because Aristotle wrote only about PEM, not about PET, as he wanted to convince his readers that truth and falsity are absolute, non-gradable opposites (cp. for example Metaphysics, end of book IV, IOIO-IOI2). 
As we have seen, a SENTENCE, as a linguistic object, may fail to express a proposition. The following sentence, for example, as presented here and now ('out of the blue'):

(8) She refused to eat.

does not express a proposition: it makes no sense to ask if it is true or false. For that to make sense, i.e. for (8) to express a proposition, the sentence must be contextually anchored, so that it is known to whom the pronoun she refers, and what the time and situation of reference are. ${ }^{3}$ Yet it is a good sentence of English, with a subject and a predicate, and an embedded infinitive. It is a sentence-type, not an utterance-token. Of some sentencetypes, however, it does make sense to ask whether they are true or false. For example, the sentence-type:

(9) All humans are mortal.

is no doubt true. Since Quine (I960) it has been customary to distinguish between OCCASION SENTENCES, which need contextual anchoring to express a proposition, and ETERNAL SENTENCES, which are true or false no matter the linguistic or situational context in which they are uttered. It was probably because of the baffling complications which he saw coming with regard to occasion sentences that Aristotle (Metaph $1027^{\mathrm{a}-\mathrm{b}}$ ) decided to ban all of them from his metaphysics and his logic. The Stoics tried to undo this ban, but modern logic has reinstated it: Russell and Quine have tried to implement a programme whereby (nearly) all occasion sentences are logically reduced to eternal sentences. This was what motivated Russell's treatment of the definite article in his famous 'Theory of descriptions' (I905), where he attempts to reduce "phrases containing the ... by far the most interesting and difficult of denoting phrases' (I905:48I) to the existential quantifier and a few propositional functions. In principle, the Russell-Quine programme amounts to an attempt at obliterating the distinction between occasion and eternal sentences, thus making the Principle of Complete Valuation applicable to all sentence-types, which will then automatically all express propositions.

But let us turn to the second subprinciple, the Principle of Binarity, which is more promising, in that its rejection delivers more truth-theoretical and logical goods. This principle can be rejected in a number of ways. One may, for example, wish to reject PEM and maintain that the opposition between true and false is not, as Aristotle insisted it was, absolute, like that between dead and alive, but gradable, like that between old and young. An elaboration of this notion leads to what is known as 'fuzzy logic', which allows for an infinite number of values between 'true' and 'false'. When all

[3] Note that the sentence The king of France is bald, said out of the blue, is normally wellanchored, since hearers will know that France is an existing country and that a country may have a king as head of state. 
intermediate values are taken together as one intermediate third value, the result is a trivalent logic with an intermediate value between 'true' and 'false'. ${ }^{4}$ Such logics defy PEM and hence the Principle of Binarity.

A different way of rejecting the Principle of Binarity consists in distinguishing different kinds of falsity. The first proposal to this effect was made in Dummett (I98I : 42 I), but without any formal elaboration. A first formal account was provided in Seuren (1985, I988), which resulted in a trivalent propositional calculus $\mathrm{PPC}_{3}$ to which I shall return below.

The point here is that a strictly bivalent logic operates with propositions that have no choice but to be either true or false. Consequently, a unary propositional operator that takes a truth value and delivers one can only be one of four functions (with ' $T$ ' for 'true' and ' $F$ ' for 'false'):
(i) $\mathrm{T} \rightarrow \mathrm{T}$
(ii) $\mathrm{T} \rightarrow \mathrm{T}$
(iii) $\mathrm{T} \rightarrow \mathrm{F}$
(iv) $\mathrm{T} \rightarrow \mathrm{F}$
$\mathrm{F} \rightarrow \mathrm{F}$
$\mathrm{F} \rightarrow \mathrm{T}$
$\mathrm{F} \rightarrow \mathrm{F}$
$\mathrm{F} \rightarrow \mathrm{T}$

(i) leaves the truth value intact and can be paraphrased as 'it is true that'. (ii) makes every proposition true, and thus corresponds to 'it is true or false that'. (iii) makes every proposition false and corresponds to 'it is true and false that'. (iv) inverts the values, and comes close to what we wish to consider negation: 'it is not so that'. The standard symbol for this negation operator is ' $\neg$ '. In terms of Figure I, it says that $s_{a}$ is situated in the complement of /A/ within $\mathbf{U}$.

All this is very neat, as neat as logicians wish their logic to be. But it does mean that the negation operator cancels all entailments except necessary truths. When we say that a sentence A ENTAILS a sentence B (i.e. A $\models B$ ), we mean that NECESSARILY, WHENEVER A IS TRUE (EXPRESSES A TRUE PROPOSITION), B IS ALSO TRUE (ALSO EXPRESSES A TRUE PROPOSITION), ON ACCOUNT OF THE MEANINGS OF A AND B. Entailment is analytically necessary consequence, in the Kantian sense of 'analytic'. Now clearly, when $A \models B$ and also $\neg A \models B$, $\mathrm{B}$ must be a necessary truth (true in all situations). For, in this strictly bivalent set-up, all situations are such that either $\mathrm{A}$ or $\neg \mathrm{A}$ is true, and if both $\mathrm{A} \models \mathrm{B}$ and $\neg \mathrm{A} \models \mathrm{B}, \mathrm{B}$ has no choice but to be true.

In empirical terms this means that if it can be established that in natural language a sentence $\mathrm{A}$ as well as its negation not-A both entail a sentence $\mathrm{B}$ which is not a necessary truth, the logic at work in language cannot be bivalent. The negation operator not cannot then correspond to the operator $\neg$ in standard bivalent logic, and room must be created for a third option, the famous 'third' excluded by PET, besides the simple opposition between truth and falsity.

Here we come to our empirical argument showing that (truth in) natural language is not bivalent. For there are plenty of cases where a sentence A

[4] Such as the trivalent logic devised by Kleene (1952) (although Kleene did not set up his trivalent logic with this purpose in mind). 
shares entailments that are not necessary truths with its negation not-A, and all these cases involve a special kind of entailment which we call 'presuppositional' (for reasons to be explained in section 7). It follows that the bivalence hypothesis for natural language falls foul of, precisely, presuppositions.

Let us consider some examples. The point about the following examples is that, as an observational matter, they do not allow for P-cancelling negation, no matter what theory one wishes to adopt to explain P-cancelling negation (cp. also Seuren I990: 447-448):

(Io) (a) All children laughed.

(b) Not all children laughed.

$\models$ there were children

(I I) (a) Only the children laughed. $\quad \models$ the children laughed

(b) Not only the children laughed. $\quad \models$ the children laughed

(I2) (a) The butler killed Jack. $\quad \models$ someone killed Jack

(b) The butler didn’t kill Jack. (Joe did) $\models$ someone killed Jack

(I3) (a) It was the butler that killed Jack. $\models$ someone killed Jack

(b) It wasn't the butler that killed Jack. $\models$ someone killed Jack

(I4) (a) Who killed Jack was the butler. $\models$ someone killed Jack

(b) Who killed Jack wasn't the butler . $\vDash$ someone killed Jack

(I5) (a) That Joe died surprised Susan. $\quad \models$ Joe died

(b) That Joe died didn't surprise Susan. $\vDash$ Joe died

(i6) (a) She doesn't mind that Joe has left. $\vDash$ Joe has left

(b) She does mind that Joe has left. $\quad \models$ Joe has left

Those believing in standard modern Predicate Calculus will, of course, immediately deny that (IOa) has an existential entailment, since that calculus says it doesn't. (IOb) will be considered all right because 'not-all' is equivalent to 'some-not' by standard conversion, and hence has existential import. As for (Ioa), however, I maintain that standard Predicate Calculus, though a great instrument for mathematical reasoning, does an injustice to natural language in this respect. One knows, of course, that Aristotelian Predicate Calculus accepted this entailment (the 'subaltern'), and that this led to its downfall because the Aristotelian calculus is unable to deal with quantification over empty sets: it PRESUPPOSES the non-emptiness of, for (I Oa, b), the set of children quantified over, and this kind of presupposition is rejected in modern Predicate Calculus as devised by Frege and Russell. ${ }^{5}$ But this does not show that modern Predicate Calculus is right with regard to language. All it shows is that this calculus rejects, and is thus unable to deal with, presuppositions, which we knew already. Aristotle wanted to reject presuppositions as well, at least in his logic, but he didn't quite succeed in mutilating his intuitive linguistic judgments to a sufficient extent, and, moreover, he lacked the formal means for implementing a logic that would

[5] See Seuren (1998: 300-320) for an extensive discussion of Aristotelian Predicate Calculus. 
allow him to do so. At this point, however, we are not so much interested in logic as in intuitive judgments of entailment, and we feel that it is inconsistent to say something like 'Yes, all children laughed. In fact, there were no children', just as we judge it inconsistent to say 'No, not all children laughed. In fact, there were no children.'

But even those who have difficulty accepting (IO) will accept (I I). One can hardly maintain that it is consistent to say that only the children laughed but that the children didn't laugh, or that not only the children laughed but that the children didn't laugh. Since (I Ib) is the sentential negation of (I Ia), we have here an absolutely clear case of a sentence B ('the children laughed') which is not necessarily true and is entailed both by another sentence A and its negation not-A. Here the curtain falls for the bivalence hypothesis.

It should be observed, in this context, that, in English, presuppositions can only be cancelled by a negation that is in construction with the finite verb form. Negation in other, 'non-canonical' positions, such as the sentenceinitial position of ( $\mathrm{IOb}$ ) and ( $\mathrm{I} \mathrm{Ib}$ ), are always P-preserving.

The examples (I2), (I3) and (I4) are cases of clefting and/or contrastive accent. Standard logical ('formal') semantics dismisses such cases as semantically irrelevant since, it is said, clefting or contrastive accent never makes a truth-conditional difference. But (I2), (I3) and (I4) show that this is not so: under negation they keep their presuppositional entailment in full force, which is not so for the same sentences without the clefting or contrastive accent. It should be noted, in passing, that clefting or contrastive accent also makes a clear truth-conditional difference under emotive intensional operators, as is shown by the consistency of, for example:

(I7) Susan complained (was angry/surprised) that it was the butler who had killed Jack, not that it was Jack whom the butler had killed.

Therefore, by the rules of its own book, logical ('formal') semantics must admit that clefting and/or contrastive accent is a semantic, and not a pragmatic phenomenon, even if it will find it hard to provide a semantic account for such phenomena in terms of its own book.

Now to example ( I5). Here we see that the factive presupposition of a thatclause cannot be cancelled by negation when the clause in question stands in sentence-initial position. This is, apparently, a general principle, whose explanation is still unclear. It also, and perhaps even more clearly, applies to cases with two that-clauses (in such cases the subject-clause is always factive, again for unknown reasons):

(I8) (a) That Joe died means that you are rich. $\quad \models$ Joe died

(b) That Joe died doesn't mean that you are rich. $\models$ Joe died

As regards (I6), here we have to do with the (weak) negative polarity item mind. In simple assertive sentences this requires a negative context, unless mind receives heavy contrastive accent evoking an echo-effect. This makes it possible to make sentence pairs like ( $\mathrm{I} 6 \mathrm{a}, \mathrm{b})$ with a polar affirmative-negative 
opposition. Such pairs also preserve the (factive) presupposition. Most negative polarity items are stronger in that they do not allow for heavy contrastive accent without a negative context. These do not allow for polar oppositions like (I6a, b). Sometimes, however, such pairs come about with a small lexical change, as in:

(I9) (a) She still lives in Paris. $\quad \models$ she has lived in Paris before

(b) She doesn't live in Paris any more. $\models$ she has lived in Paris before

Any more is a stronger negative polarity item which does not allow for a nonnegative context:

(20) *She lives in Paris any more.

Yet when one asks naive subjects what the negation is of (I9a), there is a close to I00 \% probability that they give (I9b) as their answer. We do not need, however, examples with such polarity-induced lexical switches: there are enough of them without that complication.

It must be noted that the preservation of presuppositional entailments in (I0) to (I6) is unrelated to the fact that they are occasion sentences requiring contextual anchoring for truth or falsity. We can easily make analogous examples without any contextual anchoring:

(2 I) (a) All gnomes run banks.

(b) Not all gnomes run banks.

(22) (a) Only children are innocent.

(b) Not only children are innocent.

(23) (a) Butlers steal sugar.

(b) Butlers don't steal sugar. (cooks do)

(24) (a) It is butlers that steal sugar.

(b) It isn't butlers that steal sugar.

(25) (a) Butlers are the ones who steal sugar.

(b) Butlers aren't the ones who steal sugar.

(26) (a) That men are mortal is surprising.

(b) That men are mortal isn't surprising.

(27) (a) Nobody minds that men are mortal.

Somebody does mind that men are mortal. $\models$ men are mortal

This should destroy any hope as to a bivalent semantics and truth theory, and therefore also as to a bivalent logical system for natural language. $\models$ there are gnomes

$\models$ there are gnomes

$\models$ children are inno-

cent

$\models$ children are inno-

cent

$\models$ some people steal sugar

$\models$ some people steal sugar

$\vDash$ some people steal sugar.

$\models$ some people steal sugar

$\models$ some people steal sugar

$\models$ some people steal sugar

$\models$ men are mortal

$\vDash$ men are mortal

$\vDash$ men are mortal 


\section{Classical and presuppositional entailments:}

THE SEMANTICS OF PREDICATES

In view of the observations given above it seems reasonable to make the following stipulations, which amount to a three-valued presuppositional theory of truth and satisfaction, and thus to a three-valued presuppositional semantics:

(i) Every sentence that is contextually well-anchored, and thus fit for use as an actual utterance, expresses a proposition, and therefore may have a truth value.

(ii) There are three truth values: 'true', 'minimally false', and ' radically false'.

(iii) Truth is achieved when the entities referred to by the argument terms satisfy the satisfaction conditions set by the predicate.

(iv) Most predicates have two kinds of satisfaction conditions, the PRECONDITIONS and the UPDATE CONDITIONS. The preconditions generate presuppositional entailments (presuppositions). The update conditions generate classical semantic entailments.

(v) Radical falsity results when at least one of the entities referred to by the argument terms fails to satisfy the preconditions of the predicate.

(vi) Minimal falsity results when, given full satisfaction of the preconditions, at least one of the entities referred to by the argument terms fails to satisfy the update conditions of the predicate.

Suppose I am spinning a yarn about the king of France, and as part of my fictitious story I say The king of France is bald. Now it makes perfect sense to ask if that sentence is true or false, ${ }^{6}$ and hence to treat it as expressive of a proposition. That proposition, however, cannot be true, since the entity referred to by the argument term the king of France does not satisfy the conditions set by the predicate bald, for the simple reason that in order to be

[6] As is well-known, Strawson (I950, I952 and elsewhere) insisted that the question of the truth or falsity of an assertion 'simply does not arise' when the assertion suffers from presupposition failure. The existence, however, of the massive amount of literature dealing with this very question bears witness to the fact that the question does arise. One fears that Strawson failed to distinguish between unanchored occasion sentences, such as (8) above, and well-anchored sentences that are part of a coherent text and/or fit in with available world knowledge, but whose presuppositions happen not to be all true. In the case of unanchored sentences it does indeed make no sense to enquire about their truth or falsity. For well-anchored (but radically false) sentences it makes all the sense in the world. One can see this immediately when one thinks of a mother who has just been telling her young boy to go to sleep or else the Abominable Snowman will come and punish him. Clearly, it makes a great deal of sense to the boy to know whether or not what his mother told him was true, and the moment he finds out that the Abominable Snowman does not exist he will be reassured, since that tells him that his mother's statement was in any case not true. The same point is made in Dummett (I98I: 42I). 
bald one has at least to exist, which the king of France does not do. To say simply that it is false and that therefore its negation is true leads into the quagmire from which we are trying to escape. So we distinguish between two kinds of falsity, a not so serious kind, called 'minimal falsity' (FI), for cases where all presuppositions of the sentence are fulfilled but the assertive or update content is false (in this case the conclusion is that the king of France is hirsute), and a more serious kind, called 'radical falsity' (F2), for cases where at least one of the presuppositions is not fulfilled.

We then define truth as the fulfilment of the complete set of satisfaction conditions of the predicate, and we distinguish between two kinds of satisfaction conditions, the PRECONDITIONS, which give rise to presuppositions, and the UPDATE CONDITIONS, which give rise to classical semantic entailments. Let us illustrate this for the English predicate bald (with apologies for the primitive and incomplete lexicological description):

BALD: Unary adjectival predicate.

Preconditions: $\quad$ The term referent (a) exists, (b) belongs to a category whose members are normally covered with hair, pile or tread (for tyres) in prototypical places.

Update conditions: The coverage which is normally there is largely absent.

When we now look at the sentence The king of France is bald, independently of any context, merely as a sentence-type, we can say a few things about its semantics. We can say that whenever it is true (expresses a true proposition), the entity referred to by the king of France satisfies all the conditions of the predicate bald. Thus, whenever this sentence is true, it follows, in virtue of its meaning, that the king of France really exists. This is therefore entailed by this sentence, in the precise technical sense of entailment defined above. In this case, moreover, the entailment is presuppositional. When a predicate $\mathrm{G}$ generates a presuppositional entailment of existence with respect to a specific argument term, we say that $\mathrm{G}$ is EXTENSIONAL with respect to that term. ${ }^{7,8}$

The sentence likewise entails, in virtue of the preconditions of the predicate bald, that the king of France belongs to a category (humans, in this case) whose members are normally covered with hair, pile or tread in prototypical

[7] Lexicographically, it is not necessary to indicate for each predicate whether it is existential with regard to any given term, since extensionality is the default condition. It suffices to use a special symbol (for example an asterisk) for those arguments with respect to which the predicate in question is not extensional (see Seuren 1985:252ff.).

[8] Philosophically enlightened readers will notice that this analysis requires the assumption, generally considered unpopular, of the reality of non-existing or intensional entities. I shall not go into this question here, but I refer to extensive arguments for that assumption in Seuren (1985: 472-476) and (I998: 39I-393, 452-453). 
places (hair, in this case, and on the head). This kind of entailment we call categorial presuppositional entailments. When a speaker's world knowledge tells him that the entity referred to by an argument term cannot possibly satisfy a categorial condition, we speak of a CATEGORY MISTAKE, as in, for example:

(28) Australia is bald.

Sentences containing category mistakes are necessarily radically false when used literally. They can escape radical falsity only in metaphorical usage or when the argument term is known (on the basis of contextual or situational clues) not to refer literally but via ad hoc reference, as when the expression Australia is used to refer to, for example, an Australian person.

Finally, the sentence The king of France is bald entails that the hair which normally covers the head of humans is largely absent in the case of the king of France: he is bald. This last entailment results from the update condition of the predicate bald, unlike the two previous entailments, which derive from the preconditions. We therefore say that this last entailment is a classical entailment, as opposed to the earlier ones, which are all presuppositional.

This is how the satisfaction conditions of predicates generate presuppositional and other semantic entailments (not semantically vacuous entailments, such as all necessarily true sentences, or sentences created by oraddition). ${ }^{9}$ Those entailments that follow from the preconditions are presuppositions, while those that follow from the update conditions are classical semantic entailments.

\section{Presuppositions AND Discourse StruCture}

One notes that this purely semantic account of presuppositions covers existential, factive and categorial presuppositions, but not, at least not obviously, presuppositions induced by contrastive accent and/or clefting, and presuppositions induced by focussing words like only, even or too. A more sophisticated semantics, however, in tandem with an appropriate theory of grammar, might well show that clefting and contrastive accent require a predicate (be) assigning values to parameters, and that focussing words likewise have the status of predicate at an abstract level of analysis (see Seuren I985: 295-3I3). If those analyses are tenable in principle, we have a general account of how presuppositions are induced by preconditions of predicates.

Presuppositions and classical semantic entailments are thus derivable from

[9] It may be noted in passing that the entailment schema of or-addition (any sentence A entails $\mathrm{A} \vee \mathrm{B}$, for any arbitrary $\mathrm{B}$ ) grossly violates natural semantic intuitive judgements, since a speaker may well wish to assert $A$ and refuse to assert ' $A$ or B'. This is one of the many points where logic is at odds with semantics. 
their carrier sentences on the basis of purely linguistic knowledge. This is precisely what makes them functional for efficient linguistic communication. FOR THE POINT OF PRESUPPOSITIONS IS THAT THEY EMBODY CERTAIN CONDITIONS THAT MUST BE FULFILLED IN PRECEDING DISCOURSE FOR THE CARRIER SENTENCE TO BE PROPERLY ANCHORED, AND THUS TO EXPRESS A PROPOSITION. It is assumed that the information successively provided in a coherent discourse is stored in a specific middle-term memory space called Discourse Domain (D). The process whereby the information contained by each new uttered sentence is added to $\mathbf{D}$ is called INCREMENTATION. A $\mathbf{D}$ fulfills the conditions for the incrementation of a sentence A, or i(A), when it either already contains the presuppositions $\mathrm{P}$ of $\mathrm{A}$ or ALLOWs FOR the post hoc incrementation of $\mathrm{P}$ prior to $\mathrm{i}(\mathrm{A})$. D Allows FOR $\mathrm{i}(\mathrm{X})$ just in case $\mathrm{X}$ is logically consistent with $\mathbf{D}$ and interpretable in the totality of available world knowledge.

Presuppositions are thus (together with anaphora) an important instrument for the proper contextual anchoring of a sentence. They are, moreover, extremely functional in that, in principle, they need not be expressed explicitly but can be left implicit. The fact that they are structurally (compositionally) derivable from their carrier sentence allows for their rapid post hoc incrementation (usually called 'accommodation') without it being necessary to spend time and effort over their explicit formulation and further linguistic processing. PresupPositions thus CONSTITUTE AN EXTREMELY POWERFUL DEVICE FOR SAVING TIME AND ENERGY IN LINGUISTIC COMMUNICATION.

The remaining semantic entailments, those that we have called 'classical semantic entailments', now constitute the new information left over after the presuppositions have been processed. They form what is often called the assertive content, the actual 'update' of $\mathbf{D}$, which is why we have called the corresponding satisfaction conditions 'update conditions'.

It would seem that this discourse-semantic account of presuppositions and update entailments is a great deal clearer, more coherent and more enlightening than any alternative account provided in the literature. It places presuppositions squarely within semantics, and it opens the perspective of a semantic theory which, contrary to standardly accepted formal or modeltheoretic semantics, provides a principled account of what is involved in processes of contextual anchoring. It moreover helps to provide a more principled basis for some of the weakly supported positions taken in Carston (I998), as we shall see in a moment.

\section{Trivalent propositional Calculus $\left(\mathrm{PPC}_{3}\right)$}

First, however, a few words must be said about the logical aspects of the notions that have so far been presented. If the semantics of natural language involves (at least) three truth values and a corresponding presuppositional 
machinery, it follows that any logical account of natural languge must be at least trivalent. In Seuren (I985, especially the Appendix by A. Weijters), as well as in Seuren (I988), a three-valued logic is presented that accounts for the logical properties of the presuppositional semantic system sketched above. And although, as has been said and will be argued below, it is probably unwise to let the semantics rest on the logic rather than vice versa, it is still useful to be well-informed about the logic. ${ }^{10}$

The trivalent presuppositional propositional calculus $\left(\mathrm{PPC}_{3}\right)$ developed in Seuren (I985, I988) assumes three truth values: 'true' (T), 'minimally false' (FI), and 'radically false' (F2), whose definitions are as given above. If negation is a unary propositional operator selecting the complement of a sentence A within a (sub)universe (see Figure I), then there is room for three negation operators with the following truth tables, where ' $\sim$ ' stands for 'minimal not', ' $\simeq$ ' for 'radical not', and ' $\neg$ ' for the classical negation: ${ }^{11}$

\begin{tabular}{|c|c|c|c|}
$\mathrm{A}$ & $\sim \mathrm{A}$ & $\simeq \mathrm{A}$ & $\neg \mathrm{A}$ \\
\hline $\mathrm{T}$ & $\mathrm{F} 1$ & $\mathrm{~F} 1$ & $\mathrm{~F} 1$ \\
$\mathrm{~F} 1$ & $\mathrm{~T}$ & $\mathrm{~F} 1$ & $\mathrm{~T}$ \\
$\mathrm{~F} 2$ & $\mathrm{~F} 2$ & $\mathrm{~T}$ & $\mathrm{~T}$
\end{tabular}

Figure 2

Trivalent truth tables for minimal, radical and standard negation

The minimal negation, as in $\sim \mathrm{A}$, leaves the presuppositions of $\mathrm{A}$ intact and says that there is a failure in the update conditions of the predicate of $\mathrm{A}$. The radical negation, as in $\simeq \mathrm{A}$, says that there is a failure in the preconditions of the predicate of $\mathrm{A}$. The classical negation, as in $\neg \mathrm{A}$, says that there is a failure in the satisfaction conditions of the predicate of $\mathrm{A}$. The minimal and radical negations are called 'specific negations' because they turn exactly one kind of falsity into truth. The table for disjunction in Figure 3 shows that the

[IO] Dummett (I98I : 426-427) considers precisely such a trivalent logic, but leaves the question of the truth tables open. He does say, correctly in my view, that a calculus in the spirit of Frege or Strawson, whereby the undefinedness of a proposition is infectious in the truth tables (see Seuren I985: 2 I9), is of little use from a logical point of view, since it would seriously hamper the development of any serious inference schemas (e.g. any disjunction of a proposition $\mathrm{A}$ and a proposition $\mathrm{B}$ that suffers from presupposition failure would no longer entail A). This would, in fact, force one to eliminate, again, all occasion sentences and thus reinstate the Russell-Quine programme.

[II] For a mathematical foundation of $\mathrm{PPC}_{3}$ in terms of an extended Boolean algebra, see Seuren et al. (to appear). 
classical negation is, in fact, nothing but the union (disjunction) of the specific negations.

Conjunction and disjunction in $\mathrm{PPC}_{3}$ are defined according to a simple algorithm: if ' $\mathrm{T}$ ' is ranked lowest and ' $\mathrm{F} 2$ ' highest, with ' $\mathrm{FI}$ ' in between, then conjunction selects the higher and disjunction selects the lower of the values involved. This yields the following truth tables for conjunction and disjunction, respectively, in trivalent $\mathrm{PPC}_{3}$ :

\begin{tabular}{ccccc}
\multicolumn{1}{c}{} & \multicolumn{1}{c}{$\mathrm{B}$} & & \\
\multicolumn{1}{c}{} & $\wedge$ & $\mathrm{T}$ & $\mathrm{F} 1$ & $\mathrm{~F} 2$ \\
\cline { 2 - 5 } $\mathrm{A}$ & $\mathrm{T}$ & $\mathrm{T}$ & $\mathrm{F} 1$ & $\mathrm{~F} 2$ \\
& $\mathrm{~F} 1$ & $\mathrm{~F} 1$ & $\mathrm{~F} 1$ & $\mathrm{~F} 2$ \\
& $\mathrm{~F} 2$ & $\mathrm{~F} 2$ & $\mathrm{~F} 2$ & $\mathrm{~F} 2$ \\
\hline
\end{tabular}

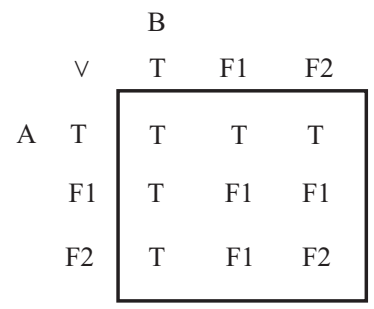

Figure 3

$\mathrm{PPC}_{3}$ truth tables for conjunction and disjunction

It has been shown (Weijters 1985 ) that $\mathrm{PPC}_{3}$ is but one instance of an infinite set of n-valued PPCs (with n-I kinds of falsity), and that classical propositional calculus is the minimal, bivalent case with only one kind of falsity. For each n-valued $\mathrm{PPC}_{\mathrm{n}}$ there are $\mathrm{n}$-I specific negations (one for each kind of falsity). Moreover, each $\mathrm{PPC}_{\mathrm{n}}$ has the classical negation as the union of all n-I specific negations. Finally, and most importantly, under the operators $\{\neg, \wedge, \vee\}$ as defined above each $\mathrm{PPC}_{\mathrm{n}}$ is logically equivalent to classical bivalent propositional calculus, or PPC $_{2}$. THIS MEANS THAT THE INTRODUCTION OF FURTHER TRUTH VALUES MAKES LOGICAL SENSE ONLY IF CORRESPONDING SPECIFIC NEGATION OPERATORS ARE ALSO INTRODUCED. With only the operators $\{\neg, \wedge, \vee\}$ any distinction between specific kinds of falsity is logically vacuous.

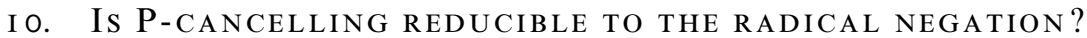

We have seen that the introduction of different kinds of falsity creates the logical space for further negations, such as the radical negation ' $\simeq$ '. The question remains, however, whether this radical negation ' $\simeq$ ' correctly represents the P-cancelling negation we find in natural language. I have, in the past, explored the possibility of a logical account of P-cancelling negation, and in doing so I discovered the rather elegant $\mathrm{PPC}_{3}$ sketched above, as well as the algorithm to extend $\mathrm{PPC}_{3}$ to any $\mathrm{PPC}_{n}(\mathrm{n}>\mathrm{I}$, with nI specific negations). Yet already in Seuren (I985: 260-266) I discussed the three main serious arguments against such an ambiguity of not, which are:

282 
(i) No language has so far been discovered that distinguishes lexically between a P-preserving and a P-cancelling negation, even though many languages have different forms for the negation in different functions.

(ii) The logically defined radical negation ' $\simeq$ ' fails to account for the metalinguistic 'echo'-effect that always accompanies P-cancelling negation.

(iii) There is a general methodological advantage to the assumption of one single negation operator (Ockham's razor).

While argument (i) can be countered by saying that there are more ambiguities shared by all languages (such as the ambiguity of There is a fly in the middle of the picture), and argument (iii) can be countered by saying that valid empirical considerations override Ockham's razor, argument (ii) sticks. It was further reinforced by Horn (1985), where attention is called to metalinguistic phenomena in general, and metalinguistic negation in particular. It was, in fact, the metalinguistic aspect, which had been missing from my account so far, that made me try out, in Seuren (I988), a position that is practically identical with what is defended, in this respect, in Carston (I998), even though Carston's theoretical premisses differ considerably from my own.

Let us briefly recapitulate the positions. Horn (1985) distinguishes between a DESCRIPTIVE and a METALINGUISTIC (use of) negation. The former is, for him, the truth-functional operator ' $\neg$ ' known from classical bivalent logic. The latter implies a correction of a previous utterance. Listeners resort to the latter interpretation when a literal or descriptive interpretation leads to inconsistency. How the metalinguistic interpretation comes about is not made clear by Horn. Horn speaks (I985: I32) of 'a built-in duality of use', glossing the metalinguistic use as "II object to $u$ ", where $u$ is crucially a linguistic utterance rather than an abstract proposition' (I985: I36). But no further explanation is provided. Typical examples of metalinguistic negation are:

(29) (a) He didn't eat some of the oranges, he ate them all.

(b) Mrs. Peppercorn is not a spinster, she's an unmarried lady.

(c) In this country we don't stick to ['skedžls], we stick to ['š $\varepsilon d j u l s]$.

(d) The king of France isn't bald - there is no king of France.

In Seuren (I988, I990) it is argued, first, that the metalinguistic interpretation of not in these cases is not a matter of pragmatic transfer, but is as fully literal as the descriptive interpretation, as appears from other cases of metalinguistic interpretation where negation plays no part:

(30) All the other girls like boys, but Mary-Lou likes guys.

Strictly speaking, (30) is ambiguous between an object-linguistic (descriptive) reading and a reading where object language and metalanguage are mixed, though the object-linguistic reading is made improbable by the fact that the 
words boy and guy are near-synonyms differing mainly in social register. The second reading of (30) can be rendered as "All the other girls like what they refer to as "boys", but Mary-Lou likes what she refers to as "guys"'. There is no reason to regard this metalinguistic reading as nonliteral or pragmatically derived, unless one wants to maintain that quoted forms are inadmissible in grammatical and/or semantic analyses. As one knows, the mixing of object language and metalanguage is strictly forbidden in standard modern logic so as to ban paradoxes of the Liar type, but any such injunction is totally unrealistic in the study of language. In fact, we find that natural language not only happily mixes object language and metalanguage but also has sophisticated means at its disposal to avoid Liar-type paradoxes without the all too strict prohibition imposed by Russell and Tarski (see Seuren I987). ${ }^{12}$

Seuren (I988, I990) also argues that cases of P-cancelling, as in (29d), form a separate subclass, contrary to Horn (I985: I35), for whom all cases of metalinguistic or corrective negation form one undivided natural class. One reason given is that Horn's own position with regard to negation entails that P-cancelling cases do not lead to inconsistency, so that no pragmatic reanalysis is required. Secondly, in (29d), but not in (29a-c), a motivating conjunction like because or for can be inserted between the first and the second (correcting) sentence. Thirdly, the not in (29a-c) is the P-preserving minimal not, not the radical not of (29d). This appears from the fact that it may occur in positions that are out of bounds to P-cancelling not, such as the sentence-initial position (see above, in connection with examples (Io) and (I I)). Consider, for example (Seuren I988: I9I):

(3I) (a) Not several but all the guests left after the row.

(b) Not Lizzy, if you please, but Her Majesty was wearing a red hat.

Note that the quantifier several, like both, is a POSITIVE POLARITY ITEM (PPI). PPIs have the property that they cannot be in the immediate scope of the Ppreserving negation, only of the P-cancelling negation. ${ }^{13}$ This means that a sentence like (3ra) should not be possible. Apparently, however, what we have in (3ra) is not the word several but the word "several", in its mention form, not its use form. Note also the difference between (32a), with not in canonical position (constructed with the finite verb form) and thus a candidate for P-cancelling use, and $(32 \mathrm{~b}, \mathrm{c})$, where not does not occur in

[I2] Note that object language and metalanguage can also be mixed in anaphora, as is shown by (i), though (ii) shows that there are limits:

(i) He has lived in Dnjepropetrovsk for twenty years, but he is still unable to pronounce it.

(ii) *Volapük means 'world speak' in it.

[13] Unless that negation stands itself in a negative context, as in:

(i) There is nobody here who wouldn't make several mistakes. (Baker 1970). 
canonical position and thus does not allow for P-cancelling (Seuren I988: I9I):

(32) (a) He did not only lose his arm. He only lost his little finger.

(b) !Not only did he lose his arm. He only lost his little finger.

(c) !He not only lost his arm. He only lost his little finger.

Interestingly, Carston holds similar views. According to Carston (I998: 3I7-320), the negation in (29a-d) should be interpreted as 'standard truthfunctional negation' (p 317), i.e. ' $\neg$ '. Yet she fails to give any indication as to how that interpretation is to be built up from the structure of the sentences involved, or even to mention the problem. She likewise agrees (1998: 334-336) that the P-cancelling cases, though metalinguistic, form a separate class, and she proposes (I998: 339-340) the form 'not ["the F is G"]' (quoted in (2) above). Again, however, there is no mention of the problem of how the negation operator could or should operate on a structure like "["the $F$ is G"]'.

Yet the problem is real. Unfortunately, there is virtually no serious literature on the grammar of metalinguistic usage: no 'grammar of quotes' is available. This places us in a dilemma. On the one hand there is the strong appeal of natural, intuitive judgments and observations with regard to Pcancelling and other metalinguistic phenomena, and one's legitimate preference for a single negation in language. On the other hand there is the lack of any formal grammatical or semantic theory linking up the interpretations that are postulated with a semantic and grammatical analysis that makes these interpretations possible.

Carston wants to maintain the unity of negation, for her the standard truth-functional negation ' $\neg$ '. She attempts to get around the dilemma by applying a pragmatic reanalysis, which, however, is badly in need of formal support. In Seuren I988 one single negation, in this case P-preserving ' ', is likewise envisaged, and the same dilemma is faced. In order to safeguard the status of negation as a propositional operator, attempts are made there to formulate general propositional schemata embodying the metalinguistic intuitive judgments. It is tentatively proposed $($ I $988:$ I 92,220$)$ that, except in cases of P-cancelling, the metalinguistic interpretation may perhaps be taken to result from an underlying propositional paraphrase of the form "the proper expression $\mathrm{V}$ in " $\mathrm{X}-\mathrm{V}-\mathrm{Z}$ " is " $\mathrm{A}$ ", , where $\mathrm{X}$ and $\mathrm{Z}$ are parts of a given sentence, and $\mathrm{V}$ is a variable ranging over expressions. A rudimentary transformational treatment is even sketched to provide a mapping relation between the paraphrastic schema on the one hand and the surface structure on the other. Yet the empirical basis of these proposals is admittedly weak. For P-cancelling cases the form 'not ["the F is G"]' is proposed (Seuren I988: 222), just as in (2) above taken from (Carston I998: 340). This is regarded as derived from a propositional schema where "the $F$ is $G$ " is paraphrased as something like "the sentence "the $F$ is $G$ " belongs to the set 
of sentences that can be anchored in the given D'. But again, although this makes a great deal of sense in terms of Discourse Semantics, the empirical support in terms of SYNTACTIC observations and generalizations is weak, to say the least. In this situation any proposal that contains a promise to solve, or at least attenuate, the dilemma should be welcomed.

In the following sections we will develop a new perspective, based on a combination of discourse semantics, speech act theory and the mixing of object language and metalanguage, which may show a way out of the dilemma of metalinguistic not. It should be noted right away, however, that this requires nothing less than a radical revision of the very foundations of present-day semantics and pragmatics, as well as of certain aspects of established logic. The revision had therefore better be generally profitable for semantics, not just for metalinguistic not.

\section{I. Logic, PRAgMatics AND SEMANTiCs}

At this point it is useful to have a fresh look at the role played by logic in semantics, and the position of pragmatics. The overall situation is not very encouraging. Logical analysis, as has been known for many centuries, too often fails to do justice to natural intuitive judgments of meaning. One only has to think of the well-known unnaturalness of logical 'or' and 'if - then' constructions. Ever since the introduction of their logical analysis by Stoic philosophers during the third century BC, there have been debates, at times vociferous and even public, ${ }^{14}$ about the deficiencies of the operators of disjunction and implication. In fact, none of the so-called truth-functional operators satisfies intuitive judgments. And, for example, often involves temporal order in language but never in logic. And other problems with and have come to light as well. ${ }^{15}$ The standard logical analysis of negation is likewise badly deficient, as we have seen, and though a trivalent analysis in terms of $\mathrm{PPC}_{3}$ brings considerable relief, it fails to answer questions to do

[I4] Kneale \& Kneale (I962: I28) inform us that the 3rd century BC Greek poet Callimachus wrote an epigram saying 'Even the crows on the rooftops caw about the nature of conditionals', which shows the amount of contemporary public interest in questions of this nature.

[15] For example, it appears that complement anaphora (Moxey \& Sanford 1986/7), as in,

(i) Few members were at the meeting. They were (all) out on the lake, having a good time.

where the pronoun they is best taken to refer to the members who were not at the meeting, is blocked by and:

(ii) Few members were at the meeting. And *they were (all) out on the lake, having a good time.

Here the complement anaphora reading is impossible. More observations of this nature can be made. In general, it seems that and is typically used to concatenate elements that make up the COMMENT of the sentence. 
with metalinguistic phenomena. These are serious faults, and many others can be pointed out, not only in propositional calculus but also in predicate calculus and in model theory. Logic, in other words, has not put up a very satisfactory performance as a theory of meaning. In this century, however, such criticisms have been quelled by the enormous prestige of standard modern logic, which is considered inviolate. The shortcomings of logic with regard to linguistic analysis have provoked little more than qualms. But given the methodology and practice followed in modern linguistics, where intuitive judgments of grammaticality and of semantic comprehension have the status of DATA, these 'qualms' must be taken as SERIOUS COUNTEREVIDENCE to the logic-based semantics that is generally accepted.

The course followed over the past few decades to remedy the deficiencies of logic-based semantics has been to invoke an auxiliary theory, pragmatics, that should explain why speakers often deviate from the logical path. But pragmatics has not been very successful in doing so. In fact, to the extent that it has to CHANGE the type-level propositional form underlying a type-level sentence to a DIFFERENT propositional form underlying a token-level utterance, its task is next to hopeless. Given the perspective prevailing in modern semantics-cum-pragmatics, it would seem much more straightforward and productive to try and remedy the main theory, logic itself, rather than resort to an auxiliary theory and saddle it with an impossible task. To some extent this is done in $\mathrm{PPC}_{3}$, but although, as we have seen, the results are nontrivial and interesting, the semantic problems are not solved by it.

An alternative course, and this is what is proposed here, would be to elevate the auxiliary theory to the status of central theory and demote the central theory to a subsidiary status. One important argument for this alternative is that it has never been made clear exactly what EXPLANATORY ROLE logic could possibly have in the semantics of natural language. The assumption of a logic machine in the mind is rightly considered absurd. But what else can logic do other than, perhaps, provide a mere logical characterization of the semantic properties of natural language propositions and the operators they contain?

The question of the proper role of logic in semantics is not easy to answer. In this century, the meaning of a sentence has been equated with the set of its entailments, or, equivalently, its truth conditions. This makes a great deal of sense, and to the extent that it does, logic is naturally called upon, since that is what logic and its derivative, logical model theory, are about. There are, however, three points to make here.

First, it must be realized that the vast majority of entailments or truth conditions cannot be captured by logic because they are due to satisfaction conditions of lexical predicates. These entailments are semantic but not logical. They become logical as soon as a CALCULus has been developed to compute them, because logic is per se a calculus. Thus, logic is of no use to explain the fact that John is dead is entailed by John has been murdered, as 
this entailment is merely semantic, not logical. Therefore, to the extent that logic, till the present day, has failed to compute semantic entailments, it is of no use to semantics. An appeal to cognitive psychology seems much more relevant here.

Secondly, the meaning of a sentence involves much more than just entailments or truth conditions (Seuren I998: 405-4IO). Speech act qualities, for example, clearly codetermine meaning but are not expressible as truth conditions: (33a) below does not mean the same as (33b).

(33) (a) He closed the door.

(b) Did he close the door?

Epithetic qualifications, such as our great provider of wisdom, contribute to meaning but not to truth conditions:

(34) (a) Where is professor Biggles? He is in a meeting.

(b) Where is professor Biggles? Our great provider of wisdom is in a meeting.

Differences in topic-comment modulation (contrastive accent) do not change truth conditions in extensional contexts, as in (I2) above or (35), but they do in emotive intensional contexts, as in (I7) above or (36). This being so it is reasonable to say that if topic-comment modulation (contrastive accent) makes a semantic difference in (36), it must do so as well in (35).:

(35) (a) Jack sold the car.

(b) Jack sold the car.

(36) (a) Marion was surprised that Jack had sold the car.

(b) Marion was surprised that Jack had sold the car.

Then, to the extent that presuppositions are derivable from predicate meanings (see section 7), they are clearly semantic. Yet the following two sentences, which differ in their presuppositions, appear to have identical truth conditions:

(37) (a) It started raining at five o'clock.

(b) Before five o'clock it did not rain, but from five o'clock on it did.

That these two sentences do indeed differ in meaning appears, again, when they are placed under an emotive operator. It does not take too much linguistic subtlety to see that the following two sentences differ in meaning:

(38) (a) Ben was surprised that it started raining at five o'clock.

(b) Ben was surprised that before five o'clock it did not rain but that after five o'clock it did.

Such observations can be multiplied at will. They show that meaning involves more than truth conditions or entailments. And to the extent that it does, logic must be deemed inadequate as a theory of meaning. 
Thirdly, it does not seem likely that logic will provide the basis for a realist theory of meaning, one that gives a causal account, in terms of really occurring structures and processes, of what the (type-level) comprehension of a sentence amounts to. Since it is commonly accepted in linguistics that a realist theory is preferable to an instrumentalist one, there is a metatheoretical clash between logic-based semantics on the one hand, and linguistic theory on the other.

But does this mean that logic is worthless for semantics? Far from it. Just as physical nature has mathematical properties, language has logical properties. And just as physics has to fall back on sometimes highly specialized forms of mathematics, linguistics, and especially semantics, cannot do without sometimes highly specialized forms of logic (and thus also of mathematics, if mathematics forms the basis of logic). If a structure or process is logically unsound, it stands little chance of being semantically (cognitively) sound. Logic thus provides an ideal, though incomplete, method for the specification of semantic problems, as well as an indispensable testground for semantic theories. In fact, recent history has shown that no serious semantics ever came about until logic had developed some, admittedly primitive, means to tackle the issues. And experience tells us that an inquiry into the logical properties of linguistic constructions often shows up hidden problems and equally often leads to surprising and highly fruitful answers and insights. A rejection of logic is about the worst mistake one can make in semantics. The second worst mistake is to think that logic is all there is to semantics.

Logic cannot be the foundation of semantics, but semantics is the proper foundation of logic. The logical properties of the sentences of natural languages are best seen as epiphenomenal on the semantic and cognitive processing of the sentences in question. They emerge when semantic processes and properties are looked at from the point of view of preservation of truth through sequences of sentences, which is the defining question of logic, not of semantics. It was Aristotle's unique and monumental achievement to have laid the foundations for this highly abstract discipline. But our respect for this achievement should not blind us to its limitations.

Moreover, if language is indeed trivalent in the manner described and argued for above, the emergent, epiphenomenal logic of language should be something like $\mathrm{PPC}_{3}$, even if it cannot be constitutive of natural language semantics. Aristotle's insistence on strict bivalence, both for his theory of truth and his logic, sprang mainly from his strong opposition to relativistic truth theories such as those propagated by the Sophists. Such theories tended to violate bivalence by violating the Principle of the Excluded Middle, in that they accepted DEGREES of truth or falsity (see section 6). A distinction between different KINDS OF FALSITY, brought about by different kinds of satisfaction conditions for predicates, such as advocated here, was not directly envisaged by Aristotle. Yet, given his decision to ban all occasion 
sentences from his logic, one may assume that he would have opposed such a move as well. What he would have said had he been faced with the observations made in (IO)-(I6) and (2I)-(27) above, is anybody's guess.

It thus seems that logic is an indispensable auxiliary tool for semantics, and that semantics, if it is to provide a realist theory of linguistic comprehension, should link up with cognitive science in the first place. Much of what is done in present-day pragmatics is then reinterpretable as straightforward semantics.

\section{2. The SOURCE OF METALINGUISTIC PHENOMENA}

But let us revert to where we left off at the end of section Io. Since the problems there centre largely around metalinguistic phenomena, it makes sense to look for the very source of these phenomena. What makes language so oblivious of the logicians' prohibition to mix object languge and metalanguage? An unsophisticated but perfectly sensible answer is this. When speech occurs, a speaker makes decisions not only about the propositional and speech act content of what he is going to say but also about the forms that he is going to use to express that content. And a listener will store in his memory not only the content of what has been said, but will remember also the actual linguistic forms that have been used (even though the physical form memory will be much shorter than that of the propositional content). These forms are there, either as prospective objects in the immediate future, or as transient objects of a passing present or very recent past. This being so, what can keep a speaker from making comments either on the forms he is going to use or on those that he has just heard? If he can speak about a gesture he has just observed or is in the process of making, why not about a sound he has just heard or is in the process of producing?

Logicians say he can't when the sound is part of the language he is using, and this rather desperate prohibition is meant to keep us from falling into the trap of the Liar paradox. This paradox, as is well-known, allegedly comes about when one says something like This very proposition is false, because, it is said, when it is true it is false, and vice versa. Kneale \& Kneale (I962: 228) do not like this prohibition "since it wrongly excludes harmless self-reference such as that of the sentence "What I am now saying is a sentence of English", They point out that in an anonymous manuscript of the fourteenth century a distinction is made between RESTRICTIO, which consists in a prohibition of mixing object language and metalanguage (just as Russell and Tarski proposed), and CASSATIO, which says that the paradoxical sentence is meaningless ('cassa'), so that there is no paradox at all, only the appearance of one.

It seems that the medieval theorists who defended CASSATIO as the solution to the Liar paradox were right (Seuren 1987). If one says This very proposition is false, then the expression this very proposition is in need of an 
actual proposition to refer to. But since a proposition requires an entity for the property expressed by the predicate to be assigned to, there isn't a proposition as long as the entity has not been identified. Hence the expression this very proposition will be forever making rounds in a vicious circle, in search of a reference object, and the sentence This very proposition is false will never express a proposition, for lack of an entity to which to assign the property of being false. There is a sentence, but no proposition, and a proposition is needed for the assignment of truth or falsity. The sentence What I am now saying is a sentence of English escapes this fate, since 'being a sentence of English' is a property of sentences, not of propositions. So we can safely ignore the 'restrictio' proclaimed by the modern logicians, and continue to mix object language and metalanguage the way we have always done. Language itself takes care of the Liar paradox.

\section{3. SPeAKing as an aCt of Social COMMitment}

But there is more to metalinguistic phenomena than just the availability of linguistic forms to talk about. Linguistic forms used in speech also fall within the speaker's responsibility, which takes us to speech act theory. Since Austin (I962) it has been generally accepted that when a speaker utters a sentence he does more than just express a proposition. Speech act theory tells us that it is not possible to express a mere proposition, such as 'Mary selling motorbikes', without any indication as to how the speaker intends the proposition to function in the situation at hand. Every utterance, indeed every use of a conventional sign, contains an element manifesting the speaker's (signer's) commitment with regard to the proposition expressed. When the conventional sign is an uttered sentence, this element is called the SPEECH ACT OPERATOR. Thus, in uttering an assertion, the speaker makes himself responsible for the truth of the proposition expressed. In uttering a question, the speaker appeals to his interlocutor(s) for a specification of either the truth value of the proposition expressed, or the value of a variable in a propositional function that will turn the function into a true proposition. In uttering a request, the speaker appeals to his interlocutor(s) to make the proposition expressed come true. In all cases the speaker interferes in a social situation, performs a social act, and he does so BY PUTTING HIMSELF ON THE LINE, as a person, with regard to the reality value of the fact represented by the proposition expressed.

This much is well-known, more or less. But it is not all. The social commitment assumed by a speaker uttering a sentence does not stop with the proposition expressed. In uttering a sentence, the speaker not only puts himself on the line with regard to a given proposition, BUT ALSO WITH REGARD TO THE FORM IN WHICH THE UTTERANCE IS PRESENTED. In other words, all speech act operators invariably involve the speaker's responsibility not just with regard to the proposition expressed, but also, though perhaps 
secondarily, to his choice of syntax and morphology, his choice of words, his phonetics and phonology - to the extent, of course, that he has a choice at all.

That this is so is perhaps best illustrated with an example. Take the case of a spoiled young man, who does nothing but spend money and is eagerly awaiting his grandmother's demise in order to cash his portion of her considerable estate. Imagine him entering the family home after a long and profligate absence, saying to his elder sister, who is preparing a meal in the kitchen:

'Hi sis, has the old lady kicked the bucket yet?'

Understandably, this infuriates her. Flaring up in anger, she retorts:

"Now listen, you little brat. First, in our family it's not "the old lady" but "grandma". Then, no, she hasn't "kicked the bucket", as you so charmingly put it. She is alive and kicking (though not any buckets, I dare say). And third, even if she were no longer alive, she wouldn't have "kicked the bucket" but she would have "deceased" or "passed away". I hope this answers your question, and I also hope it teaches you some manners and some language, though it's probably too late for that. And now, get out of my kitchen, or I'll kick yóur bucket!'

This passage is full of linguistic mysteries, ${ }^{16}$ which we shall not try to solve here. But one thing is clear. There is a continuous, intricate mixing of propositional content belonging to the object language and metalinguistic commentary, during the whole of which the brat's sister holds him fully responsible for his linguistic behaviour, which includes not only the insolent question about grandma's health but also his abominable choice of words.

The fact that speaking, and therefore verbal communication in general, is by definition a matter of entering a social commitment, primarily with regard to the propositional content expressed but in a secondary sense also with regard to the forms used, has never been properly exploited in semantic theory. So far, semantic arguments have largely been considered LOGICAL in nature. We shall now see whether it makes sense to say that semantic arguments are at bottom of a LEGAL character.

\section{4. A REINTERPRETATION OF NEGATION AS A REJECTION OPERATOR}

Given the double commitment to both the content of the proposition expressed and the forms used to do so that is present in all speech acts, we may well ask ourselves whether the problems we are having with

[I6] Among these is the fact that the last sentence (I'll kick yoúr bucket) is not a threat to kill the addressee, but merely a threat to kick him in whatever it is that one kicks a person in, in such circumstances, and referred to here, in an ad hoc but eloquent fashion, as your bucket. 
metalinguistic phenomena may be clarified, or even solved, in the context of speech act theory. The first thought that comes to mind is whether the propositional operators that are standardly considered truth-functional, in particular not, and, or and if...then, may not allow for an alternative semantics not based on logic but on their interaction with speech act qualities. Their logical properties will not have to be denied, but will be taken to be just that: logical properties, not a semantic definition. A further exploration of this thought seems worth while, since it might well throw some new light on the age-old misgivings about the semantic inadequacies of logical analyses mentioned in section I I.

Leaving aside, in this context, the operators and, or and if...then, we concentrate on not. The most straightforward account of not in terms of manner of incrementation under speaker's commitment is to say that not is an instruction to ban its argument clause A from incrementation in some discourse (sub)domain D (cp. Seuren 1985: 330). It does so under the assumption that A fulfills all conditions of contextual anchoring, which accounts for the fact that (this) not is restricted to update conditions and thus $\mathrm{P}$-preserving. In normal cases, all a speaker wants to do in uttering not- $A$ is to make it clear that $\mathbf{A}$, whose papers for $\mathbf{D}$ are, so to speak, in perfect order, should be excluded from incrementation in $\mathbf{D} .{ }^{17}$

Metalinguistic form correction, as in (29a-c), (3Ia, b) or (39b) below is a special case of increment exclusion. In metalinguistic form correction the speaker makes it clear that a specific form used in the discourse at hand (and thus available to the discourse participants) should not pass without protest. Such corrections are a normal part of any ongoing discourse, and the negation used is the ordinary minimal negation, as was shown in the examples (3Ia, b) above, where form-correcting not occurs in noncanonical positions, reserved for P-preserving minimal not.

Metalinguistic form correction always involves contrastive accent and sometimes also clefting. Since these are devices used to focus on certain elements that have been or are being called into question, it is reasonable to treat metalinguistic form correction as belonging to the category of cases where an element of a sentence is singled out for special focussing. There is, of course, a variety of grammatical and semantic proposals on the market for

[17] This account of normal standard not does not suffer from the fact that not may be in the scope of a higher operator, as in:

(i) Many children did not laugh.

For such cases, the mechanics of Discourse Semantics automatically restricts the (ban on the) incrementation of the propositional function ' $x$ did (not) laugh' to a plural address that has been set up for 'many children'. Interestingly, this discourse-semantic approach may well shed some light on the curious fact, totally neglected in the literature, that languages have problems with the normal grammatical negation of unreduced conjunctive, disjunctive, or conditional sentences. Negative sentences cán be negated grammatically, but the superimposed, higher negation is then necessarily metalinguistic and P-cancelling (Seuren 1985: 233, I988: I86). 
the treatment of such cases, and it cannot be our purpose here to go into that maze of questions. All we can do here is provide a paraphrase that shows the parallel mechanisms of ordinary (descriptive) and metalinguistic contrastive focussing, illustrated in (39a) and (39b), respectively:

(39) (a) Not John but Harry will serve the wine.

(b) It's not the mail you are waiting for but the post.

(39a) is now read as something like 'not[the $\mathrm{x}$ such that $\mathrm{x}$ will serve the wine is JOHN]; the $\mathrm{x}$ such that $\mathrm{x}$ will serve the wine is HARRY' (a structure closely resembling lambda abstraction). The metalinguistic form-correcting reading of (39b) corresponds to: "not[the $\mathrm{x}$ such that "you are waiting for $\mathrm{x}$ " is the correct form is "the MAIL"; the $\mathrm{x}$ such that "you are waiting for $\mathrm{x}$ " is the correct form is "the POST" ". In both cases we have a descriptive occurrence of not.

So far we have looked at not as a means to manifest the rejection of an increment that could have been made, with metalinguistic form correction as a special case. But now suppose a speaker wants to exclude A from $\mathbf{D}$ on the grounds that $\mathbf{D}$ itself must, in his opinion, be revised in such a way that A's contextual anchoring will no longer be in order. This speaker feels that it is high time to put a stop to $\mathbf{D}$ as it has been developed so far by others, as things are getting out of hand (or not to accept the change of $\mathbf{D}$ caused by the post hoc accommodation of some presupposition of A). This more radical rejection of $\mathrm{A}$ cannot be expressed simply by the use of not over a possible propositional incrementation of $A$, as in the form 'not [A]', since this implies an acceptance of A's contextual entry papers, its presuppositions. For such cases language has, apparently, made a special provision, in that the operator not can also be used over the quoted form of A, giving rise to the form 'not ["A"]', with the specific interpretation that $\mathrm{i}(\mathrm{A})$ already made by a different speaker in $\mathbf{D}$ is rejected on account of A's presuppositional properties. In this case one or more presuppositions of A must be removed from the existing $\mathbf{D}$. The presuppositions to be removed must then be specifically mentioned, as is done in $(3 \mathrm{a}-\mathrm{c})$ above.

This analysis provides a new interpretation for the form "not ["A"]', which preserves the unity of not as one single operator of rejection: not is allowed to reject not only an ordinary propositional increment that may be made, but also, on presuppositional grounds, an increment i(A) already made but to be removed (together with one or more of its presuppositions). We are now no longer hamstrung by the logical analysis of not, which requires a propositional form for the negation to stand over. This requirement either prevented the unity of not or, if it allowed for a unitary not, required a complicated and linguistically unmotivated paraphrase in propositional terms. The operator not, in other words, is now no longer an operator that can only stand over a PROPOSITION, owing to its logical properties, but has become an operator that implies a commitment to reject 
an OBJECT. The object in question can be a possible propositional increment to a given discourse domain or subdomain, or, as has been said, an increment already made.

Now, with not no longer as a truth-functional propositional operator but as an element that operates on linguistic objects more generally, we distinguish two main categories of use:

(i) unmarked P-preserving negation: not[A:] rejection of proposition expressed by A.

(ii) marked P-cancelling negation: not["A"]: rejection of existing i(A) with P-removal.

We observe that focussing constructions are a special case of (i), and that metalinguistic form correction is a special case of focussing. Both the categories (i) and (ii) imply a rejection, but the object of rejection differs according to the category.

This analysis is clearly still very rudimentary. Further detailed research would have to show whether it is tenable at all, and if so, under what restrictions and conditions. But at this still primitive stage of the analysis, it can be observed that it gives further substance to Carston's formally unsupported proposal (I998: 340 ) to treat the P-cancelling negation as being of the form 'not [" the F is G"]', as well as to the 'gloss' proposed by Horn (1985: I36) for metalinguistic negation generally and already quoted earlier: " II object to $u$ ", where $u$ is crucially a linguistic utterance rather than an abstract proposition'. What is proposed here is, in fact, a generalization of this gloss to all cases of negation, with different possible values for $u$. It is here that we find Horn's 'built-in duality of use' (I985: I32).

This way of looking at negation does not imply a rejection of its logical analysis. On the contrary, to the extent that one is interested in formally specifying entailments, which is the business of logic, the logical account of not (in terms of $\mathrm{PPC}_{3}$ ) is probably correct and certainly helpful and suggestive. But the primary semantic function of not is not to change the truth value of the proposition in its scope, but to exclude it from the 'common ground' established between speaker and hearer for the purpose of contextual anchoring.

Regarding the argument of not as a linguistic object, which is either an increment to be made, or an increment already made, simplifies the grammatical problem mentioned above considerably. It is now no longer necessary to forge a paraphrase that has PROPOSITIONAL FORM for the argument of the P-cancelling or metalinguistic negation. All we need is an OBJECT of the proper kind that can be rejected at any stage of the incrementation process. The grammar will then have to be fitted out with a few devices, such as a well-motivated and precisely formulated procedure for erasing quotes. But this looks a great deal less arbitrary than the deletion of large chunks of text, as implied in the proposals in Seuren (I988). In fact, this 
now begins to throw some light on the question of why the radical, Pcancelling negation (category (ii)) can only occur in certain grammatically defined positions (for English, in construction with the finite verb form), which are normally reserved for high sentence negation.

\section{i 5. Conclusion}

Starting from Carston's (I998) analysis of negation and presupposition, we quickly discovered that a less cavalier treatment of formal details inevitably leads to a questioning of the bivalence hypothesis in the treatment of truth and meaning in natural language. A closer inspection of some empirical data, mostly of a presuppositional nature, then convinced us that this hypothesis is untenable. We also found that it makes sense to distinguish between two different kinds of falsity, a minimal kind, which preserves presuppositions, and a radical kind, where some presupposition must be denied. So as to bolster this double concept of falsity, the trivalent propositional calculus $\mathrm{PPC}_{3}$ was presented in outline, with a reference to Weijters (I985), Seuren (I988) and Seuren et al. (to appear) for formal underpinnings. At the same time, however, it became clear that logic is in principle unable to provide an adequate account of meaning, if only because it stumbles over central semantic phenomena, in particular the discourse properties of presupposition, metalinguistic usage and speech act qualities. This again made us reconsider the status of logic with regard to semantics, and hence also the status of pragmatics. We decided to demote logic to the rank of an auxiliary, albeit indispensable, discipline within the precinct of semantics. Its main task is the description and specification of the entailment-inducing properties of sentences in terms of a logical system. The core element of semantic processing is now seen to lie in processes of discourse incrementation, driven and constrained by presuppositions.

This, together with the failure of logic to account for metalinguistic usage and speech act properties, made us more vividly aware of the fact that speech is principally an activity whereby social, sometimes even legal, commitments are taken on, normally with respect to the propositional content of an utterance (which may be a comment on a form used or to be used), but often also with regard to a whole sentence. It was felt that this way of looking at speech and language might well open up a totally new perspective for semantic theory. It appeared that negation, in particular, is open to a commitment-based analysis whereby negation is seen as an operator that rejects either the incrementation of a propositional content (which may involve a comment on the propriety of a linguistic form that has been or is to be used) or a previously uttered and incremented sentence, which is removed from the current discourse on account of presupposition failure. In this analysis, negation is no longer a propositional operator taking a proposition and yielding a proposition, but an operator over linguistic 
PRESUPPOSITION, NEGATION AND TRIVALENCE

objects, which may be increments that can be, or increments that have been made. In the former case we have the minimal, P-preserving negation. In the latter case we have the radical, $\mathrm{P}$-cancelling negation. $\mathrm{PPC}_{3}$ describes the logical properties of the minimal and the radical negation. The commitmentbased account in terms of discourse incrementation maintains the basic unity of not, while at the same time it explains the metalinguistic character of radical not. Carston's (I998) position is thus largely vindicated, but on different theoretical grounds, better called 'semantic' than 'pragmatic'.

\section{REFERENCES}

Austin, J. L. (I962). How to do things with words. The William James lectures delivered in Harvard University in I955. Edited by J. O. Urmson. Oxford: Clarendon Press.

Baker, C. L. (1970). Double negatives. Linguistic Inquiry I. I69-186.

Carston, R. (1998). Negation, 'presupposition' and the semantics/pragmatics distinction. Journal of Linguistics 34. 309-350.

Dummett, M. (I98I). Frege. Philosophy of language (2nd edn.). Cambridge, Mass.: Harvard University Press.

Horn, L. R. (I985). Metalinguistic negation and pragmatic ambiguity, Language 6I. I 2 I-I 74.

Gazdar, G. (I979). Pragmatics, implicature, presupposition, and logical form. New York-San Francisco-London: Academic Press.

Kleene, S. C. (1952). Introduction to metamathematics. Amsterdam: North-Holland.

Kneale, W. \& Kneale, M. (I962). The development of logic. Oxford: Clarendon Press.

Moxey, L. M. \& Sanford, A. J. (I986/7). Quantifiers and focus. Journal of Semantics 5. I89-206.

Quine, W. V. O. (1960). Word and Object. Cambridge, Mass.: MIT Press.

Russell, B. (I905). On denoting. Mind I4. 479-493.

Seuren, P. A. M. (1985). Discourse Semantics. Oxford: Blackwell.

Seuren, P. A. M. (I987). Les paradoxes et le langage. Logique et Analyse 30. 365-383.

Seuren, P. A. M. (1988). Presupposition and negation. Journal of Semantics 6. I75-226.

Seuren, P. A. M. (1990). Burton-Roberts on presupposition and negation. Journal of Linguistics 26. $425-453$.

Seuren, P. A. M. (1998). Western linguistics. An historical introduction. Oxford: Blackwell.

Seuren, P. A. M., Capretta, V. \& Geuvers, H. (to appear). The logic and mathematics of occasion sentences. Language and Philosophy.

Strawson, P. F. (I950). On referring. Mind 59. 320-44.

Strawson, P. F. (1952). Introduction to logical theory. London: Methuen.

Weijters, A. (1985). Presuppositional propositional calculi. Appendix to Seuren (1985).

Author's address: Max Planck Institute for Psycholinguistics,

P. O. Box $3 I 0$,

6500 AH Nijmegen,

The Netherlands.

E-mail:p.seuren@mpi.nl 